\title{
Genetic testing for breast cancer: Where are health care providers in the decision process?
}

Christine M. Velicer, $M S^{1,2}$, and Stephen Taplin, $M D, M P H^{2,3}$

\begin{abstract}
Purpose: To identify BRCA1/2 knowledge, genetic testing intentions, and communication patterns in breast cancer survivors (survivors). Methods: A population-based survey was conducted of 276 female survivors diagnosed between the ages of 40 and 49 and living 5 to 10 years postdiagnosis. Results: Of the $79 \%$ who responded, $8 \%$ spoke with health care providers and 53\% spoke with relatives about testing. Few (26\%) correctly answered over half the $B R C A$ knowledge questions. Intention to obtain testing varied (26-67\%), depending on insurance coverage. Conclusion: Health care providers and survivors seldom discuss BRCA testing. Providing information to survivors would increase their ability to make informed testing decisions. Genetics in Medicine, 2001:3(2):112119.
\end{abstract}

Key Words: breast cancer, BRCA1, BRCA2, genetic testing, genetic counseling

As medical science advances our understanding of the relationship between genetics and disease, tests for hereditary predisposition to disease will become more commonplace. $\mathrm{Pa}$ tients will increasingly face the question of whether to obtain genetic testing, and health care providers may be an important source of credible information. Understanding how patients obtain their genetic testing information and share it with family members is critical for assessing how well the informed decision-making process is working and where health care providers fit into this process. A current case in point is testing for mutations in the hereditary breast/ovarian cancer genes (BRCA1 and BRCA2).

The details of BRCA testing are complex and can be confusing. Only a small group of women are suitable candidates for $B R C A$ testing (e.g., women with strong family history of premenopausal breast cancer), and even then, the majority of tests will be negative. BRCA1 and BRCA2 mutations are estimated to account for only $2-4 \%$ of all breast cancer cases for women between the ages of 15 and 69 at diagnosis, and for 2-9\% of breast cancer cases for women diagnosed between the ages of 40 and $49 .{ }^{1}$ Estimates of lifetime breast cancer risk for BRCA1 and BRCA2 mutation carriers range from 40 to $95 \%$, depending on the populations sampled and individual risk factors. ${ }^{1-6}$ Absence of a mutation does not imply negligible breast cancer risk. Instead, such individuals will still have, at a minimum, the baseline breast cancer risk of U.S. women with similar risk factors. BRCA1 mutations (and to a lesser degree, BRCA2 mu-

\footnotetext{
From the ${ }^{1}$ Department of Epidemiology, University of Washington; ${ }^{2}$ Center for Health Studies, Group Health Cooperative of Puget Sound; ${ }^{3}$ Department of Family Medicine, University of Washington, Seattle, Washington.

Stephen Taplin, MD, MPH, Center for Health Studies, Group Health Cooperative of Puget Sound, 1730 Minor Avenue, Suite 1600, Seattle, WA 98101.

Received: September 15, 2000.

Accepted: November 17, 2000.
}

tations) are also associated with increased risk of ovarian cancer. ${ }^{1,4}$ The estimated lifetime risk of ovarian cancer in BRCA1 carriers in a recent population-based study is $28 \% .^{1}$ If a $B R C A$ mutation is identified, treatment options to reduce breast cancer risk include tamoxifen, prophylactic mastectomy, and prophylactic oophrorectomy. ${ }^{7,8}$ However, the efficacy of tamoxifen for mutation carriers has not yet been confirmed, and prophylactic mastectomy or oophorectomy may not be desirable for many mutation carriers.

Little is currently known regarding whether health care providers are discussing $B R C A$ testing with their cancer patients. We found only one study, in which $16 \%$ of physicians of women currently under treatment for breast cancer reported talking with their patients specifically about BRCA testing. ${ }^{9}$ Long-term breast cancer survivors (5+ years) are typically reintegrated into mainstream practice because they no longer need specialized oncology care.

It is also not known if survivors of premenopausal breast cancer are discussing BRCA testing with their relatives. Such discussions may be important to allay fears, share information, and/or identify potential risks. We found only qualitative reports of communications within families regarding BRCA testing. ${ }^{10}$ Additionally, we found no population-based studies of $B R C A$ knowledge, attitudes, and testing intentions in breast cancer patients or survivors. These individuals typically should be the first recipients of testing in a family. If the survivor does not have a $B R C A$ mutation, it is unlikely that other blood relatives would benefit from $B R C A$ testing.

The objectives of our study were (1) to determine whether a population-based sample of long-term breast cancer survivors speak with their health care providers and relatives about BRCA genetics; (2) to determine survivors' BRCA knowledge, attitudes, and intentions to obtain testing; and (3) to solicit opinions regarding preferred sources of information about $B R C A$ genetics. 


\section{MATERIALS AND METHODS}

\section{Participants}

Study participants were women enrolled in Group Health Cooperative of Puget Sound (GHC), a nonprofit health maintenance organization (HMO). Eligible participants had an initial diagnosis of invasive breast cancer or ductal carcinoma in situ (DCIS) 5 to 10 years prior to June 30, 1998, and were between the ages of 40 and 49 at the time of diagnosis. A total of 276 survivors were identified. This population was selected because women diagnosed under the age of 50 are more likely to have a heritable form of breast cancer ${ }^{6}$ and also to have children currently reaching child-bearing age where issues regarding BRCA mutations may be of heightened concern. Women younger than 40 were not selected because they were too few in number.

The primary data source for cancer diagnosis was the Cancer Surveillance System, one of nine standard U.S. Surveillance Epidemiology and End Results (SEER) cancer registries. Because some current GHC enrollees may have been diagnosed outside the SEER area prior to joining GHC, we also accessed self-reported information on breast cancer collected by GHC's screening program. ${ }^{11,12}$

\section{Survey construction and dissemination}

In January 1999, self-administered questionnaires were mailed to the study population in a four-wave approach, based on methods described in Dillman and Armstrong et al. ${ }^{13,14} \mathrm{We}$ used the Health Belief Model and the Theory of Reasoned Action as the theoretical framework to guide survey development and analysis. ${ }^{15,16}$ Applied to a genetic testing scenario, the models suggest that sociodemographics, knowledge of genetics, attitudes toward testing, and opinions of others are important factors that influence intent to obtain genetic testing. In turn, intent to obtain testing is a key factor in the decision process to actually undergo testing. Our survey, therefore, included questions on each of these factors. For comparability, most knowledge and attitude questions were similar to those used in previous research. ${ }^{17-19}$ In addition, respondents were asked to assess the helpfulness of various types of information sources on BRCA. "Helpfulness" was defined as an answer of 3, 4 , or 5 on a 5 -point Likert scale from "not at all" to "very much."

The survey was developed and pretested with assistance of a focus group of five long-term breast cancer survivors enrolled at GHC. These women represented a range of ages, lifestyles, and continuing problems associated with breast cancer. Our study was conducted under the supervision and guidelines of the GHC Center for Health Studies Human Subjects Review Committee.

\section{Data analysis}

Data were analyzed in SPSS Version 7.5 for Windows and SAS for Windows, Release 6.12. Analyses included descriptive statistics, ANOVAs, Pearson correlations, and bivariate and multivariate unconditional logistic regression. Regression analyses were used to describe the association between intent to obtain testing and other factors in the genetic testing decision process. For ease of interpretation and consistency with previous studies, the regression variables were dichotomized. However, to ensure that important information was not lost by dichotomizing, the regression analyses were also conducted using continuous and categorical variables.

Two separate dependent variables were used as measures for intention to obtain BRCA testing: (1) "I plan to have a genetic test for breast cancer only if my insurance covers the cost"; and (2) "I plan to have a genetic test for breast cancer, even if I have to pay for it myself." Both measures used 4-point Likert scales ranging from "strongly disagree" to "strongly agree," which we then dichotomized, comparing those who "somewhat or strongly agreed" to those who "somewhat or strongly disagreed."

The independent variable "knowledge" was dichotomized based on whether more than $50 \%$ of seven true/false $B R C A$ knowledge questions were answered correctly. Other independent variables included education, employment status, age, income, marital status, communication with health care providers regarding genetic testing, communication with family regarding genetic testing, family history of breast and ovarian cancer, other health behaviors such as smoking status, and attitude toward testing.

We used two dichotomous independent variables for attitude: "benefits" and "limitations" of BRCA testing. These variables were developed from 14 attitude questions with responses ranging from "strongly disagree" to "strongly agree" on 4-point Likert scales. Factor analysis (principal components analysis with Varimax rotation) indicated that the benefits and limitations comprised two distinct factors, with good reliability (Cronbach's alpha coefficient for standardized variables $=$ 0.82 and 0.78 , respectively). The variables representing the "benefits" and the "limitations" of BRCA testing were then dichotomized, comparing those whose overall "somewhat or strongly agreed" to those who "somewhat or strongly disagreed."

\section{RESULTS}

The survey response rate was 79\% (217 of 276 women). An additional 14 women were mailed the survey but excluded as eligible participants because two had recently died, four had undeliverable addresses, and eight did not believe they met the 5-10 year invasive or DCIS diagnostic criteria. An analysis of nonrespondents conducted using GHC's databases indicated no statistically significant differences in means between respondents and nonrespondents for age at diagnosis, estimated number of primary care visits/year, estimated total health care costs/year, years since initial diagnosis, and type of cancer (invasive or DCIS).

Sociodemographic and medical characteristics of respondents are shown in Table 1. The mean age at initial diagnosis was 44.4 years, and the average time since that diagnosis was 
Table 1

Selected sociodemographic and medical characteristics of 5- to 10-year breast cancer survivors

\begin{tabular}{|c|c|c|}
\hline Variable & No. & $\%$ \\
\hline \multicolumn{3}{|l|}{ Current age $(n=216)$} \\
\hline $45-49$ yr & 56 & 25.9 \\
\hline $50-54$ yr & 111 & 51.4 \\
\hline $55-60 \mathrm{yr}$ & 49 & 22.7 \\
\hline \multicolumn{3}{|l|}{ Education $(n=212)$} \\
\hline High school or less & 46 & 21.7 \\
\hline Some college/tech school & 78 & 36.8 \\
\hline Graduated college & 42 & 29.8 \\
\hline Graduate-level studies & 46 & 21.7 \\
\hline \multicolumn{3}{|l|}{ Ethnicity $(n=211)$} \\
\hline White & 195 & 92.4 \\
\hline Black & 5 & 2.4 \\
\hline Asian/Pacific Islander & 10 & 4.7 \\
\hline Native American/Eskimo/Aleut & 1 & 0.5 \\
\hline Hispanic $(n=207)$ & 3 & 1.4 \\
\hline Ashkenazi Jewish $(n=204)$ & 10 & 4.9 \\
\hline \multicolumn{3}{|l|}{ Family status } \\
\hline Currently married/significant relationship $(n=193)$ & 153 & 79.3 \\
\hline Have children $(n=191)$ & 161 & 84.3 \\
\hline Have any daughters $(n=198)$ & 121 & 61.1 \\
\hline Employed $(n=189)$ & 144 & 76.2 \\
\hline \multicolumn{3}{|l|}{ Income $(n=198)$} \\
\hline$<\$ 20,000$ & 11 & 5.6 \\
\hline$\$ 20,000-35,000$ & 34 & 17.2 \\
\hline$\$ 35,001-50,000$ & 39 & 19.7 \\
\hline$\$ 50,001-75,000$ & 45 & 22.7 \\
\hline$>\$ 75,000$ & 66 & 33.3 \\
\hline Don’t know & 3 & 1.5 \\
\hline \multicolumn{3}{|l|}{ Health behavior/family history } \\
\hline Current smoker $(n=217)$ & 20 & 9.2 \\
\hline Pap smear within last 4 years $(n=209)$ & 188 & 90.0 \\
\hline Last mammogram $<2$ years ago $(n=210)$ & 187 & 89.0 \\
\hline $\begin{array}{l}\text { At least one first-degree relative with breast cancer } \\
\qquad(n=217)\end{array}$ & 58 & 26.7 \\
\hline $\begin{array}{l}\text { At least one first-degree relative with ovarian cancer } \\
\qquad(n=217)\end{array}$ & 15 & 6.9 \\
\hline
\end{tabular}

Number of respondents (less missing values) is presented in parentheses next to each variable.

7.3 years. Fourteen percent experienced a recurrence and the average time since recurrence was 2.5 years.

Respondents reported more discussions about breast cancer genetics/BRCA testing with relatives than with health care pro- viders (Table 2). Survivors were most often the conversation initiators in the family (70.5\%), followed by daughters (26.8\%) and sisters $(21.4 \%)$.

Table 3 shows BRCA awareness and knowledge scores and the percentage of women correctly answering seven true/false questions. The mean number of correct true/false answers was two. Of women who were conversation initiators, $62 \%$ answered less than half the true/false $B R C A$ questions correctly. Of women who spoke with relatives specifically about seeking $B R C A$ testing, $12 \%$ incorrectly thought they must have an altered gene because they already had breast cancer and $49 \%$ did not know the answer to this question. No women who indicated that a brother or son was the conversation initiator correctly answered the following true statement, "A father can pass down the altered BRCA genes to his daughter."

Most women had a positive attitude toward benefits of $B R C A$ testing (Table 4 ). Over $60 \%$ agreed or strongly agreed with all seven $B R C A$ positive attitude statements. Typically less than half agreed or strongly agreed with seven BRCA negative attitude statements. Women who answered more than $50 \%$ of the knowledge questions correctly were approximately $47 \%$ less likely to have a positive attitude toward testing compared with those who had lower knowledge levels $(P=0.095)$. No significant relationship between knowledge and negative attitude was observed.

Intent to obtain testing differed according to whether the individual must pay for the test or whether their insurance covers it (Table 4). Only $26 \%$ intended to obtain testing if they have to pay for it, and $93.1 \%$ of these women were willing to pay no more than $\$ 200$, out of a range from $\$ 25$ to $\$ 2,000$.

\section{Table 2}

Communications about $B R C A$ testing among breast cancer survivors' families and health care providers

\begin{tabular}{lcc}
\hline Variable & No. & $\%$ \\
\hline $\begin{array}{l}\text { Spoke with health care provider about genetic } \\
\quad \text { testing }(n=204)\end{array}$ & 17 & 8.3 \\
$\begin{array}{l}\text { Spoke with blood relatives about breast cancer } \\
\quad \text { genetics }(n=210)\end{array}$ & 112 & 53.3 \\
$\begin{array}{l}\text { Spoke with relatives about whether to seek } \\
\quad \text { information on } B R C A \text { testing }(n=108)\end{array}$ & 43 & 39.8 \\
$\begin{array}{l}\text { Conversation initiators within families who spoke } \\
\quad \text { about breast cancer genetics }(n=112)^{a}\end{array}$ & & \\
$\quad$ Breast cancer survivor & 79 & 70.5 \\
$\quad \begin{array}{l}\text { Daughter of survivor } \\
\text { Sister of survivor }\end{array}$ & 30 & 26.8 \\
Spouse/partner of survivor & 24 & 21.4 \\
Son of survivor & 10 & 8.9 \\
Brother of survivor & 7 & 6.3 \\
Other & 2 & 1.8 \\
\hline
\end{tabular}

Number of respondents (less missing values) is presented in parentheses next to each variable.

${ }^{a}$ Respondents could check all that applied. 
Table 3

Knowledge of BRCA genetics among 5- to 10-year breast cancer survivors

\begin{tabular}{|c|c|c|}
\hline Variable & No. & $\%$ \\
\hline \multicolumn{3}{|l|}{$\begin{array}{l}\text { Knowledge and communications regarding } B R C A \\
\text { genetics }\end{array}$} \\
\hline $\begin{array}{l}\text { Read "fair amount or a lot" about genetic testing } \\
\text { for breast cancer }(n=208)\end{array}$ & 36 & 17.3 \\
\hline $\begin{array}{l}\text { Answered }>50 \% \text { of true/false questions correctly } \\
\quad(n=217)\end{array}$ & 56 & 25.8 \\
\hline \multicolumn{3}{|l|}{ Correctly answered "true" } \\
\hline $\begin{array}{l}\text { Women without altered } B R C A \text { gene can still get } \\
\text { breast cancer }(n=205)\end{array}$ & 111 & 54.1 \\
\hline $\begin{array}{l}\text { Father can pass down altered } B R C A \text { genes to his } \\
\text { daughter }(n=206)\end{array}$ & 36 & 17.5 \\
\hline $\begin{array}{l}\text { Women with breast cancer before menopause } \\
\text { more likely to have altered } B R C A \text { gene than } \\
\text { women who develop breast cancer after } \\
\text { menopause }(n=206)\end{array}$ & 35 & 17.0 \\
\hline $\begin{array}{l}\text { Women with altered } B R C A \text { gene at higher risk } \\
\text { for ovarian cancer }(n=204)\end{array}$ & 1 & 0.5 \\
\hline \multicolumn{3}{|l|}{ Correctly answered "false" } \\
\hline $\begin{array}{l}\text { All women with altered } B R C A \text { gene will get } \\
\text { breast cancer }(n=206)\end{array}$ & 97 & 47.1 \\
\hline $\begin{array}{l}\text { Since I already had breast cancer, I must have an } \\
\text { altered } B R C A \text { gene }(n=206)\end{array}$ & 70 & 34.0 \\
\hline $\begin{array}{l}\text { Women with more than two people in } \\
\text { immediate family with breast cancer will have } \\
\text { an alteration in either BRCA1 or BRCA2 }(n= \\
\text { 206) }\end{array}$ & 33 & 16.0 \\
\hline
\end{tabular}

Number of respondents (less missing values) is presented in parentheses next to each variable.

Approximately $67 \%$ planned to obtain testing only if their insurance covers it.

Two variables were significantly associated with intent to obtain testing "even if they had to pay for it," based on unadjusted logistic regression analyses (Table 5). First, women with a more positive attitude toward testing were 5.8 times as likely to intend testing "even if they had to pay for it," compared with women with a less positive attitude $(P=0.005)$. Second, women who talked with relatives about $B R C A$ testing were over twice as likely to intend testing, compared with those who had not spoken with relatives $(P=0.020)$. Similar to the bivariate analyses, the multivariate logistic regression analysis showed an association between "intention to obtain testing even if the individual has to pay for it" and two variables: positive attitude toward testing (odds ratio [OR], 5.5; 95\% confidence interval $[\mathrm{CI}], 1.6-18.9)$ and talking about testing with relatives (OR, 2.2; CI, 1.1-4.4).

Four factors were significantly associated with intent to obtain testing "only if insurance covers it" (Table 5), based on unadjusted logistic regression analyses. First, married women were 2.4 times as likely to intend testing, compared with unmarried women $(P=0.020)$. Second, women with a more positive attitude toward testing were 2.2 times as likely to in-
Table 4

Attitudes and intentions regarding $B R C A$ testing among 5- to 10-year breast cancer survivors

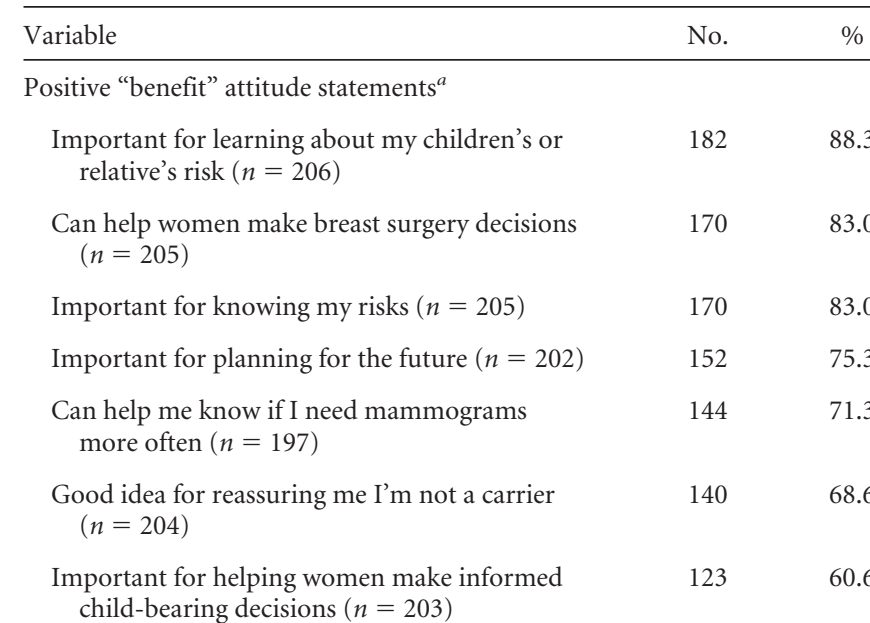

Negative "limitations" attitude statements ${ }^{a}$

Concerned about losing insurance if I had an altered $B R C A$ gene $(n=202)$

Would feel less healthy if I had altered gene $(n=207)$

Worry about effect this news would have on my family if I were a BRCA carrier $(n=203)$

Testing is bad idea because might not be $100 \%$ accurate $(n=204)$

Worry that the results may not stay confidential $(n=208)$

Would feel singled out if I had altered gene $(n=206)$

Could not handle it emotionally if I had altered gene $(n=204)$

Attitudes about availability of testing ${ }^{a}$

Once genetic testing is available, it should be offered to everyone $(n=207)$

Once genetic testing is available, it should only be offered to those people who have a reason to think they have an altered gene $(n=205)$

Intentions to receive testing $^{a}$

Intends to receive testing even if she has to pay for it herself $(n=197)$

Intends to receive testing only if covered by insurance $(n=199)$

${ }^{a}$ Respondents were asked how much they agree with these statements. "Agreement" was measured as responding "somewhat agree" or "strongly agree" on a 4-point scale, including "strongly disagree" and "somewhat disagree." Number of respondents (less missing values) is presented in parentheses next to each variable.

tend testing, compared with women with a less positive attitude $(P=0.035)$. Third, women with any daughters were 2.2 times more likely to intend testing, compared to women with no daughters $(P=0.011)$. Lastly, women with any first-degree family history of breast cancer were $47 \%$ less likely to intend to 
Table 5

Factors associated with intent to obtain BRCA testing among 5- to 10-year breast cancer survivors

\begin{tabular}{|c|c|c|c|c|c|}
\hline \multirow[b]{2}{*}{ Variable/subgroup } & \multirow[b]{2}{*}{$n(\%)$} & \multicolumn{2}{|c|}{$\begin{array}{l}\text { Intent to obtain testing even if } \\
\text { respondent has to pay for it }\end{array}$} & \multicolumn{2}{|c|}{$\begin{array}{l}\text { Intent to obtain testing only if } \\
\text { insurance covers it }\end{array}$} \\
\hline & & OR $(95 \% \mathrm{CI})^{a}$ & $P$ value & OR $(95 \% \mathrm{CI})^{a}$ & $P$ value \\
\hline \multicolumn{6}{|l|}{ Socioeconomic factors } \\
\hline$>\$ 35,000$ & $150(76.9)$ & $0.81(0.38-1.75)$ & 0.592 & $0.64(0.30-1.37)$ & 0.252 \\
\hline$<\$ 35,000$ & $45(23.1)$ & & & & \\
\hline \multicolumn{6}{|l|}{ Age } \\
\hline \multicolumn{6}{|l|}{ Education } \\
\hline$>$ High school & $166(78.3)$ & $0.62(0.30-1.30)$ & 0.208 & $1.54(0.76-3.12)$ & 0.226 \\
\hline High school or less & $46(21.7)$ & & & & \\
\hline \multicolumn{6}{|l|}{ Marital status } \\
\hline Married & $153(79.3)$ & $0.68(0.30-1.53)$ & 0.353 & $2.43(1.15-5.15)$ & 0.020 \\
\hline \multicolumn{6}{|c|}{ Knowledge and attitude about $B R C A$ genetics } \\
\hline \multicolumn{6}{|c|}{ Correctly answered } \\
\hline$>50 \%$ questions & $56(25.8)$ & $1.10(0.55-2.23)$ & 0.787 & $0.89(0.46-1.72)$ & 0.727 \\
\hline$<50 \%$ questions & $161(74.2)$ & & & & \\
\hline \multicolumn{6}{|c|}{ Positive attitude toward testing } \\
\hline Yes & $145(78.0)$ & $5.83(1.70-19.96)$ & 0.005 & $2.19(1.06-4.54)$ & 0.035 \\
\hline No & $41(22.0)$ & & & & \\
\hline \multicolumn{6}{|c|}{ Negative attitude toward testing } \\
\hline Yes & $51(25.9)$ & $1.68(0.82-3.45)$ & 0.160 & $1.24(0.60-2.53)$ & 0.561 \\
\hline No & $146(74.1)$ & & & & \\
\hline \multicolumn{6}{|c|}{ Communications and family history } \\
\hline \multicolumn{6}{|c|}{ Talked with health care provider about $B R C A$ genetics } \\
\hline Yes & $58(26.7)$ & $1.00(0.49-2.05)$ & 0.997 & $0.53(0.27-1.01)$ & 0.054 \\
\hline No & $159(73.3)$ & & & & \\
\hline \multicolumn{6}{|c|}{ Any first-degree relatives with ovarian cancer } \\
\hline Yes & $15(6.9)$ & $1.13(0.34-3.76)$ & 0.848 & $0.86(0.28-2.70)$ & 0.801 \\
\hline No & $202(93.1)$ & & & & \\
\hline Any daughters & & & & & \\
\hline Yes & $121(61.1)$ & $1.36(0.69-2.68)$ & 0.377 & $2.23(1.20-4.14)$ & 0.011 \\
\hline No & $77(38.9)$ & & & & \\
\hline Health behaviors & & & & & \\
\hline Pap smear within last & & & & & \\
\hline Yes & $188(90.0)$ & $1.08(0.37-3.13)$ & 0.890 & $0.85(0.31-2.32)$ & 0.751 \\
\hline No & $21(10.0)$ & & & & \\
\hline Mammogram within 1 & & & & & \\
\hline Yes & $187(89.0)$ & $1.71(0.55-5.32)$ & 0.351 & $1.88(0.77-4.62)$ & 0.167 \\
\hline No & $23(11.0)$ & & & & \\
\hline Current smoker & & & & & \\
\hline Yes & $20(9.2)$ & $0.30(0.068-1.35)$ & 0.118 & $1.92(0.61-6.04)$ & 0.263 \\
\hline No & $197(90.8)$ & & & & \\
\hline
\end{tabular}

OR, unadjusted odds ratio; $95 \% \mathrm{CI}$, 95\% confidence interval.

${ }^{a} P$ values at or below 0.05 in boldface type. 
obtain testing only if insurance covers it compared to women with no first-degree family history $(P=0.054)$.

Multivariate logistic regression demonstrated an association between "intent to obtain testing only if insurance covers it" and three factors: (1) marital status (OR, 3.91; CI, 1.56-9.81), (2) positive attitude toward test (OR, 3.72; CI, 1.60-8.69), and (3) having any daughters (OR, 2.27; CI, 1.07-4.82). Unlike the unadjusted regression results, the multivariate results did not show a significant relationship between having a first-degree family history of breast cancer and "intention to obtain testing only if insurance covers it." To confirm that dichotomizing variables did not result in the loss of important information, we also performed the above regression analyses using continuous and categorical variables and obtained similar results.

It is possible that women visiting their health care providers more often may have different opinions than other respondents. However, using ANOVAs and Pearson correlations, we did not observe significant associations between annual number of physician visits and the following variables: knowledge of $B R C A$ genetics, attitude toward BRCA testing, and intention to obtain testing.

It is also possible that women at higher risk for a $B R C A$ mutation might have different opinions than women at lower risk. Approximately $31 \%$ of our respondents may be at higher risk for a $B R C A$ mutation, because they had breast cancer under the age of 50 and had a first-degree relative with breast and/or ovarian cancer. Women with a family history answered $39 \%$ of the true/false BRCA knowledge questions correctly, while women without the family history answered $24 \%$ of the questions correctly $(P=0.001)$. Also, $23 \%$ of women with a family history heard "a fair amount or a lot" about genetic testing for breast cancer, while only $15 \%$ of women without a family history heard "a fair amount or a lot." Additionally, women with a family history were more likely to have discussed genetic testing with a health care provider (19\% vs. $4 \%$ ) $(P=0.001)$.

Respondents thought a number of sources and types of information on BRCA genetics would be helpful. Most women $(80.6 \%)$ indicated that an informational booklet on BRCA genetics would be helpful, followed by discussions with doctors or women's health care specialists $(79.8 \%)$, discussions with health educators $(70.4 \%)$, informational videos $(66.1 \%)$, summaries of Internet sites with genetic testing information (60.4\%), informational group classes (48.9\%), and discussions with a group of breast cancer survivors (47.9\%).

\section{DISCUSSION}

Our results suggest that health care providers and long-term breast cancer survivors are not discussing BRCA genetics with each other. Only $8.3 \%$ of our sample spoke with health care providers about genetic testing, while $53 \%$ spoke with relatives. We also found that survivors played key roles as $B R C A$ conversation initiators in their families and, therefore, may be an important information conduit for $B R C A$ testing in the family. However, the survivors had a limited understanding of
$B R C A$ genetics, which could compromise an informed decision-making process for themselves and their family members. Our respondents had lower levels of BRCA knowledge than reported in existing studies involving female first-degree relatives of affected individuals, members of hereditary breastovarian cancer families, and general population studies. Only $17.3 \%$ our sample reported hearing "a fair amount" or "a lot" about genetic testing for breast cancer (Table 3). In contrast, other studies reported awareness ranging between 35\% and $83 \% .{ }^{17,20,21}$ Also, our sample correctly responded to an average of only 2 of 7 true/false questions, which is lower than reported in several other studies. ${ }^{17,18,22}$ Even among the higher risk group in our sample, knowledge of genetic testing for breast cancer was approximately 35\% lower than prior studies, and discussions about genetic testing with health care providers were minimal. ${ }^{17,18,22}$

Several explanations regarding the lower level of knowledge in our study participants are possible. Knowledge may be limited because so few have spoken about breast cancer genetics with their health care provider. Additionally, unlike several previous studies, no participants in this study (to our knowledge) are involved in research protocols specifically targeting high-risk families of known mutation carriers. Further, our survey specifically targeted long-term breast cancer survivors in a population-based setting. Many previous studies were not population-based, and no previous studies looked at longterm survivors. Also, other studies may have focused on more recently diagnosed women, who may have been actively discussing genetics with their friends, family, and physicians; such individuals may have a better recollection of their discussions. Finally, studies several years ago were occurring when the discovery of $B R C A 1$ and $B R C A 2$ were covered in the news media. The level of knowledge in breast cancer survivors at that point in time may have been higher due to more active news coverage.

Consistent with several previous studies, the benefit of $B R C A$ testing cited most often $(88.3 \%)$ was learning about children's or relative's risk. ${ }^{18,19,23,24}$ The disadvantage of testing cited most often $(50.9 \%)$ was concern about losing insurance if an altered gene is found. This is consistent with the results of Lerman et al. ${ }^{18}$

Consistent with prior research, respondents with more knowledge about $B R C A$ genetics had a less positive attitude toward the benefits $(P=0.095)$ and a less positive attitude was associated with lower intention to obtain testing. ${ }^{18,23,25}$ This suggests that providing women with information on breast cancer genetics may not necessarily increase their intention to obtain testing. Increased understanding among survivors and their families- not necessarily increased intention to obtain testing among women who may not benefit from testing- is a desirable outcome from a medical perspective.

Our study is the first to highlight how strongly the intent to obtain genetics testing is tied to insurance coverage for breast cancer survivors. Only $26.4 \%$ would seek BRCA testing if they had to pay for it themselves, whereas over $67 \%$ would seek testing if their insurance covered it. We found only one other 
study that distinguished between intent to obtain testing when the test is free versus when payment is required. ${ }^{26}$ In that study, conducted among women in a waiting room of an OB/GYN office and at a mammography center, approximately $60 \%$ would accept the test if they had to pay, whereas over $93 \%$ would accept the test if it were free. Other studies involving first-degree relatives of breast cancer patients, members of hereditary breast-ovarian cancer families, and the general population did not consider the influence of test cost and found moderate to high levels of intention (60-95\%). ${ }^{21,26,27}$

In addition to attitude toward testing and cost issues, familial factors may influence the testing decision. Such factors include the survivor's marital status, communications with relatives, having daughters, and having a first-degree family history. These factors were significantly associated with intent, depending on insurance coverage (Table 5).

Health care providers and genetic counselors may have a variety of $B R C A$ education options available for breast cancer survivors. Respondents indicated that written materials, discussions with doctors or health educators, videos, and the Internet would be helpful ways to obtain BRCA information. Brochures at mammography centers and doctors' offices are potential options, as are Internet sites. Respondents preferred written materials $(80.6 \%)$ in contrast to a recent focus group session by Bernhardt et al., in which interactive group education with supplementary printed materials was preferred. ${ }^{25}$ Only $47.9 \%$ of our respondents indicated discussion groups would be helpful. It is possible that the results of Burnhardt et al. are more reflective of a self-selected sample already predisposed to participate in groups. Nonetheless, both results show a desire for written material.

A limitation of our research is the cross-sectional study design, from which causality cannot be established. For example, it is possible that women spoke with relatives about $B R C A$ testing after having already decided to undergo testing, and not that speaking with relatives increased their intent to obtain testing. Nonetheless, these associations provide valuable insight into factors in the genetic testing decision process, and verify some of the work of previous researchers in other populations. Another limitation is that we do not have information regarding whether these women were actually tested. Testing is covered in this health plan after discussions with a geneticist, but we did not have access to data on whether this service was used. However, only five women in the study indicated that they had heard "a lot" about genetic testing for breast cancer. If a large number of women in our cohort had undergone testing, we would expect this number to be higher.

Additionally, we did not have information regarding our respondents' sources of information about BRCA genetics. Also, it would have been interesting to compare respondents' self-reported knowledge of $B R C A$ to chart reviews or a survey of health care providers to identify what $B R C A$ discussions or education, if any, may have transpired and when it occurred. Finally, our measure of willingness to pay for BRCA testing could have been more refined, such as "willingness to pay if the insurer covered testing but the individual had a 20\% copayment of $\$ 516$.”

In summary, our study is the first population-based study of long-term breast cancer survivors' communications, knowledge, attitudes, and intentions regarding BRCA testing. The demographic characteristics of women enrolled in our HMO are similar to the Puget Sound area of Washington State, though slightly higher in income level. ${ }^{28}$ Thus, our results can likely be generalized to survivors in this region who were diagnosed between 1983 and 1998 when they were 40 to 50 years old, and possibly to women of similar sociodemographic and survivorship status elsewhere in the country. Given that our sample includes women of higher incomes with access to medical care and these individuals have very limited knowledge of breast cancer genetics, we have no reason to suspect that conditions would be better in the general U.S. population.

Long-term breast cancer survivors have less BRCA knowledge than expected from previous studies. Our results suggest that increasing survivors' knowledge of BRCA is unlikely to result in a large influx of testing requests. Rather, it will provide information needed to make well-informed decisions. Though health care providers currently appear to be playing a limited role in the BRCA testing decision process, long-term survivors would find their input helpful. Providing genetic information to patients in a variety of ways will be an important new challenge for medical care providers.

\section{Acknowledgments}

This project was funded by grant CA63731 from the National Cancer Institute (NCI). While the NCI supported this project, the design, implementation, analysis, and interpretation were the sole responsibility of the authors. The authors acknowledge the assistance of Diana S.M. Buist, PhD, Deborah Casso, Christi Hanson, Deborah Seger, and Nancy Snell.

\section{References}

1. Whittemore AS, Gong G, Itnyre J. Prevalence and contribution of BRCA1 mutations in breast cancer and ovarian cancer: results from three U.S. population-based casecontrol studies of ovarian cancer. Am J Hum Genet 1997;60:496-504.

2. Couch FJ, DeShano ML, Blackwood MA, Calzone K, Stopfer J, Campeau L, Ganguly A, Rebbeck T, Weber B. BRCA1 mutations in women attending clinics that evaluate the risk of breast cancer. N Engl J Med 1997;336:1409-1415.

3. Claus EB, Risch N, Thompson WD. Genetic analysis of breast cancer in the Cancer and Steroid Hormone Study. Am J Hum Genet 1991;48:232-242.

4. Struewing JP, Hartge P, Wacholder S, Baker SM, Berlin M, McAdams M, Timmerman MM, Brody LC, Tucker MA. The risk of cancer associated with specific mutation of BRCA1 and BRCA2 among Ashkenazi Jews. N Engl J Med 1997;336:14011407.

5. Easton DF, Ford D, Bishop DT. Breast Cancer Linkage Consortium. Breast and ovarian cancer incidence in BRCA1-mutation carriers. Am J Hum Genet 1995;56: 265-271.

6. Krainer M, Silva-Arrieta S, Fitzgerald MG, Shimada A, Ishioka C, Kanamaru R, MacDonald DJ, Unsal H, Finkelstein DM, Bowcock A, Isselbacher KJ, Haber DA. Differential contributions of BRCA1 and BRCA2 to early-onset breast cancer. NEngl J Med 1997;336:1416-1421.

7. Hartmann LC, Schaid DJ, Woods JE, Crotty TP, Myers JL, Arnold PG, Petty PM, Sellers TA, Johnson JL, McDonnell SK, Frost MH, Jenkins RB. Efficacy of bilateral prophylactic mastectomy in women with a family history of breast cancer. $N$ Engl J Med 1999;340:77-84.

8. Rebbeck TR, Levin AM, Eisen A, Snyder C, Watson P, Cannon-Albright L, Isaacs C, Olopade O, Garber JE, Godwin AK, Daly MB, Narod SA, Neuhausen SL, Lynch HT, 
Weber BC. Breast cancer risk after bilateral prophylactic oophorectomy in BRCA1 mutation carriers. J Natl Cancer Inst 1999;91:1475-1479.

9. Polednak AP. Do physicians discuss genetic testing with family-history-positive breast cancer patients? Conn Med 1998;62:3-7.

10. DudokdeWit AC, Tibben A, Frets PG, Meijers-Heijboer EJ, Devilee P, Klign JGM, Oosterwijk JC, Niermeijer MF. BRCA1 in the family: a case description of the psychological implications. Am J Med Genet 1997;71:63-71.

11. Taplin SH, Mandelson MT, Anderman C, White E, Thompson RS, Timlin D, Wagner EH. Mammography diffusion and trends in late-stage breast cancer: evaluating outcomes in a population. Cancer Epidemiol Biomarkers Prev 1997;6:625-631.

12. Carter AP, Thompson RS, Bourdeau RV, Andenes J, Mustin H, Straley H. A clinically effective breast cancer screening program can be cost-effective, too. Prev Med 1987;16:19-34

13. Dillman DA. Mail and telephone surveys: the total design method. New York: Wiley, 1978.

14. Armstrong BK, White E, Saracci R. Principles of exposure measurement in epidemiology. Monographs in epidemiology and biostatistics. Vol 21. New York: Oxford University Press, 1994.

15. Janz NK, Becker MH. The Health Belief Model: a decade later. Health Educ Q 1984; 11:1-47.

16. Ajzen I, Fishbein M. Understanding attitudes and predicting social behavior. Englewood Cliffs: Prentice Hall, 1980.

17. Wonderlick AL, Fine BA. Knowledge and breast cancer genetics among breast cancer patients and first-degree relatives of affected individuals. J Genet Couns 1997;6: 111-129.

18. Lerman C, Narod S, Schulman K, Hughes C, Gomez-Caminero A, Bonney G, Gold K, Trock B, Main D, Lynch J, Fulmore C, Snyder C, Lemon SJ, Conway T, Tonin PO, Lenoir $\mathrm{G}$, Lynch H. BRCA1 testing in families with hereditary breast-ovarian cancer. JAMA 1996;275:1885-1892.
19. Lynch HT, Lemon SJ, Durham C, Tinley ST, Connolly C, Lynch JF. A descriptive study of BRCA1 testing and reactions to disclosure of test results. Cancer 1997;79: 2219-2228.

20. Mouchawar J, Byers T, Cutler G, Dignan M, Michael S. A study of the relationship between family history of breast cancer and knowledge of breast cancer genetic testing prerequisites. Cancer Detect Prev 1999;23:22-30.

21. Tambor ES, Rimer BK, Strigo TS. Genetic testing for breast cancer susceptibility: awareness and interest among women in the general population. Am J Med Genet 1997;68:43-49.

22. Hughes C, Gomez-Caminero A, Benkendorf J, Kerner J, Osaacs C, Barter J, Lerman C. Ethnic differences in knowledge and attitudes about BRCA1 testing in women at increased risk. Patient Educ Couns 1997;59:459-466.

23. Jacobsen PB, Valdimarsdottir HB, Brown KL, Offit K. Decision-making about genetic testing among women at familial risk for breast cancer. Psychosom Med 1997; 59:459-466.

24. Struewing JP, Lerman C, Kase RG, Giambarresi TR, Tucker MA. Anticipated uptake and impact of genetic testing in hereditary breast and ovarian cancer families. Cancer Epidemiol Biomarkers Prev 1995;4:169-173.

25. Bernhardt BA, Geller G, Strauss M, Helzlsouer KJ, Stefanek M, Wilcox PM, Holtzman NA. Knowledge of breast cancer genetics among breast cancer patients and first-degree relatives of affected individuals. J Genet Couns 1997;6:207-222.

26. Chaliki H, Loader S, Levenkron JC, Logan-Young W, Hall WJ, Rowley PT. Women's receptivity to testing for a genetic susceptibility to breast cancer. Am J Public Health 1995;85:1133-1135.

27. Ulrich CM, Kristal AR, White E, Hunt JR, Durfy SJ, Potter JD. Genetic testing for cancer risk: a population survey on attitudes and intention. Community Genet 1998; 1:213-222.

28. Campbell KM, Holm K. Preventive service utilization among older women: a comparison of HMO members, private insurance policy holders, and Medicare recipients. Washington State Department of Health, Center for Health Statistics, 1995. 